\title{
PROFIL PETANI DALAM MEMANFAATKAN PEKARANGAN DI DESA OTAM (INDUK) KECAMATAN PASSI BARAT KABUPATEN BOLAANG MONGONDOW
}

\author{
Ma'dika \\ Martha Mareyke Sendow \\ Jean Fanny Junita Timban
}

\begin{tabular}{ll}
\hline Naskah diterima melalui Website Jurnal Ilmiah agrisosioekonomi@unsrat.ac.id & : Kamis, 26 Desember 2019 \\
Disetujui diterbitkan & : Rabu, 8 Januari 2020 \\
\hline
\end{tabular}

\begin{abstract}
This study aims to look at the profile of farmers in utilizing the yard in Otam (Induk) Village, Passi Barat District, Bolaang Mongondow Regency. This research was conducted from September to November 2019. The method of selecting samples was done purposively, namely to farmers who own a plots of land. The data used are primary data and secondary data. Primary data was collected through interviews with 50 respondents, namely farmers owning their plots. Secondary data were obtained from the Otam Village Office. Data analysis in this study uses descriptive analysis in the form of tables and simple calculations. The results showed that the grounds in the village of Otam (Induk) are owned by farmers who mostly have junior high school education. Yard land is used by farmers for various types of plants. Most of the plots are planted Farmers who plant their plots with spice plants for cooking by 40 percent while farmers who plant medicinal plants for treat disease only 16 percent. While farmers who grow vegetables $24 \%$, and those who grow fruits $20 \%$ in their yard. Live pharmacy plants, namely: cat's whiskers, bitter, ginger, and ginger. Plants that include a living kitchen in the form of: Galangal, Chinese onions, kulaci (solation), and onion stems. Plants that include vegetables are mustard greens, cabbage, carrots, tomatoes, leilem vegetables and Japanese cucumbers. While the fruit plants include: duku, avocado, langsa, soursop, durian and mango. ${ }^{* e p r m *}$
\end{abstract}

Keywords: farmers, utilization of land around the house, spice plants, medicinal plants

\begin{abstract}
ABSTRAK
Penelitian ini bertujuan untuk melihat profil petani dalam memanfaatkan pekarangan di Desa Otam (Induk) Kecamatan Passi Barat Kabupaten Bolaang Mongondow. Penelitian ini dilakukan dari bulan September sampai November 2019. Metode pemilihan sampel dilakukan secara sengaja (purposive sampling) yaitu pada petani pemilik lahan pekarangan. Data yang digunakan adalah data primer dan data sekunder. Data primer dikumpulkan melalui wawancara pada 50 responden yaitu petani pemilik lahan pekarangan. Data sekunder diperoleh dari Kantor Desa Otam. Analisis data dalam penelitian ini mengunakan analisis deskriptif dalam bentuk tabel serta perhitungan sederhana. Hasil penelitian menunjukkan bahwa pekarangan di Desa Otam (Induk) yang dimiliki sendiri petani yang kebanyakan berpendidikan SMP. Lahan pekarangan dimanfaatkan oleh petani untuk berbagai jenis tanaman. Pekarangan kebanyakan ditanami Petani yang menanami lahan pekarangannya dengan tanaman dapur hidup sebesar 40 persen sedangkan petani yang menanami tanaman apotik hidup.hanya 16 persen. Sedangkan petani yang menanam sayuran-sayuran $24 \%$, dan yang menanam buah-buahan $20 \%$. Tanaman apotik hidup yaitu: kumis kucing, sambiloto, jahe, dan temulawak. Tanaman yang termasuk dapur hidup berupa: Lengkuas, bawang cina, kulaci (solasi), dan batang bawang. Tanaman yang termasuk sayuran adalah sawi, kol, wortel, tomat, sayur leilem dan ketimun Jepang. Sedangkan yang termasuk tanaman buah yaitu: duku, alpokat, langsa, sirsak, durian dan mangga. ${ }^{*}$ eprm*
\end{abstract}

Kata kunci : petani, pemanfaatan pekarangan, tanaman dapur hidup, tanaman apotik hidup 


\section{PENDAHULUAN}

\section{Latar Belakang}

Indonesia merupakan negara agraris, dalam era yang semakin berkembang ini, salah satu tuntutan bagi sebuah negara berkembang adalah pembangunan nasional. Pembangunan nasional akan terlaksana dengan baik apabila ada koordinasi dari segenap masyarakatnya. Hakikat pembangunan nasional adalah pembangunan manusia atau individu seutuhnya dan masyarakat seutuhnya (Ayuningtias, 2012).

Usman (2008) dalam Istiqomah (2018), mengatakan bahwa di dalam masyarakat, dapat dikemukakan dua macam keadaan yaitu terdapat kemiskinan sekaligus kesenjangan. Kemiskinan merupakan salah satu masalah sosial yang amat serius, tumbuh di setiap dimensi dan sendi-sendi kehidupan bermasyarakat. Pemerintah telah mencanangkan berbagai program pengentasan kemiskina seperti bedah rumah, sedangkan kesenjangan menurut Kamus Besar Bahasa Indonesia adalah ketidak seimbangan, ketidak simetrisan atau sebagai jurang pemisah antara sikaya dan simiskin. Kesenjangan ekonomi yang terjadi di masyarakat Indonesia adalah rendahnya kualitas SDM dan terbatasnya lapangan pekerjaan.

Usaha meningkatkan produksi dan pendapatan usaha tani tidak akan berhasil tanpa penggunaan teknologi baru baik dibidang teknis budidaya, benih, obat-obatan dan pemupukan. Oleh karena itu pembangunan ekonomi pertanian secara langsung maupun tidak langsung akan berdampak pada pengurangan penduduk miskin dan meningkatan kesejahteraan sosial juga dapat berjalan seperti apa yang sudah dicita-citakan. Pembangunan pertanian adalah suatu proses yang ditunjukkan untuk selalu menambah produksi pertanian untuk tiap-tiap konsumen yang sekaligus menambah pendapatan dan produktifitas (Lynn, 2013 dalam Welang dkk, 2016).

Permasalahan mendasar yang dihadapi petani adalah kurangnya pengetahuan tentang cara bercocok tanam dengan baik, teknologi, dan organisasi tani yang masih lemah. Dengan permasalahan ini yang perlu di pahami bahwa sumberdaya manusia itu perlu di bina agar pengetahuan mengelola usaha pertanian dalam rangka meningkatkan produksi pertanian berpengaruh terhadap kesejahteraan petani (Ayuningtyas, 2012).
Sulawesi Utara adalah salah satu daerah yang memiliki tanah yang subur dan strategis sehingga potensi pertanian bisa menghasilkan bahan pangan yang besar untuk memenuhi kebutuhan masyarakatnya khususnya Desa Otam (Induk) Kecamatan Passi Barat Kabupaten Bolaang Mongondow yang sebagian besar penduduknya adalah masyarakat petani yang mengusahakan berbagai macam tanaman untuk kelangsungan hidupnya dan menambah pendapatan.

Pengembangan sumberdaya manusia pertanian dinilai sangat penting karena meningkatnya kualitas sumberdaya manusia, akan mampu mengatasi problema pertanian yang penuh risiko tidak hanya dalam peningkatan produksi, tetapi juga dalam peningkatan pendapatan dan pengembangan usaha pertanian. Dengan demikian, di Sulawesi Utara kegiatan pembangunan pertanian banyak ditekankan melalui pemberdayaan sumberdaya manusia, upaya ini dilakukan melalui kegiatan penyuluhan pertanian yang antara lain dilakukan melalui pendekatan kelompok (Handoko, 2008).

Lahan pekarangan di pedesaan mempunyai potensi yang besar dalam rangka mendukung ketahanan pangan rumah tangga, hal ini dapat dibuktikan dengan pendapatan keluarga yang timbul dari pemanfaatan lahan pekarangan. Jika dikembangkan akan memberikan pendapatan ekonomi rumah tangga, serta kesejatraan masyarakat sekitar. Alasan mengambil desa Otam (Induk) sebagai tempat penelitian karena didesa tersebut dapat tumbuh berbagai jenis tanaman baik tanaman bua-buahan, tanaman sayuran, tanaman dapur hidup, dan apotik hidup.

\section{Rumusan Masalah}

Yang menjadi rumusan masalah adalah bagaimana memanfaatkan pekarangan dengan baik di Desa Otam (Induk) Kecamatan Passi Barat Kabupaten Bolaang Mongondow.

\section{Tujuan Penelitian}

Untuk mengidentifikasi profil petani dalam memanfaatkan pekarangan di Desa Otam (Induk) Kecamatan Passi Barat Kabupaten Bolaang Mongondow.

\section{Manfaat Penelitian}

Penelitian ini diharapkan memberikan manfaat kepada masyarakat tentang profil petani dalam memanfaatkan pekarangan di Desa Otam (Induk) Kecamatan Passi Barat Kabupaten Bolaang Mongondow sehingga bisa menambah pendapatan keluarga. 


\section{METODE PENELITIAN}

\section{Tempat dan Waktu Penelitian}

Penelitian ini dilaksanakan di Desa Otam (Induk), Kecamatan Passi Barat, Kabupaten Bolaang Mongondow. Penelitian berlangsung selama kurang lebih 3 bulan yaitu dari bulan September sampai bulan November 2019.

\section{Metode Pengumpulan Data}

Pengambilan data menggunakan data primer dan data sekunder, dimana data primer di dapat dari petani secara langsung dengan menggunakan daftar pertanyaan (kuesioner), dan data sekunder diperoleh dari pihak pemerintah yaitu dari Kantor Desa Otam (Induk), Kecamatan Passi Barat, Kabupaten Bolaang Mongondow.

\section{Metode Pengambilan Sampel}

Pengambilan sampel dalam penelitian ini adalah petani yang memiliki pekarangan. Pengambilan sampel dalam penelitian ini menggunakan metode purposive sampling yaitu teknik pengambilan sampel secara sengaja dengan jumlah responden yang diambil yaitu 50 orang karena dianggap mewakili petani pekarangan di Desa Otam (Induk), Kecamatan Passi Barat, Kabupaten Bolaang Mongondow.

\section{Konsep dan Pengukuran Variabel}

Variabel yang diukur dalam penelitian ini yaitu:

1. Karakteristik Responden

a. Umur responden, yaitu dilihat dari umur kelompok tani pekarangan yang dinyatakan dalam tahun.

b. Tingkat Pendidikan, yaitu dilihat dari pendidikan terakhir yang ditempuh responden diukur dalam tahun.

c. Jenis mata pencaharian, yaitu dilihat dari jenis pekerjaan yang dilakukan oleh responden.

d. Luas Pekarangan.

e. Jenis tanaman yang tumbuh dipekarangan :

1) Tanaman buah

2) Apotik hidup

3) Dapur hidup

4) Tanaman sayuran.

\section{Metode Analisis Data}

Data yang diperoleh dalam penelitian ini diolah secara deskriptif dan disajikan dalam bentuk tabel. Data yang dikumpulkan terbagi menjadi dua bagian, yaitu; Data primer adalah data yang diperoleh dari responden dan diolah sehingga bisa di sajikan dalam bentuk tabel penelitian. Sedangkan Data Sekunder yaitu: Data yang diperoleh atau diambil dari kantor Desa dan ditulis dalam penelitian ini untuk menjelaskan keadaan Desa Otam (Induk) Kecamatan Passi Barat Kabupaten Bolaang Mongondow.

\section{HASIL DAN PEMBAHASAN}

\section{Sejarah dan Arti Nama Desa Otam}

Pada Zaman dahulu kala Desa Otam masih merupakan hutan belantara konon menurut cerita dari generasi ke generasi, leluhur Desa Otam berasal dari daerah Pantai Utara dari Mokoidal. Tidak di ketahui dengan dari mana sesungguhnya leluhur Desa Otam itu berasal, serta apa yang menyebabkan sehingga Nenek Moyang Desa Otam itu meninggalkan tempat yang lama kemudian mencari tempat pemukiman yang baru. Yang jelas dari cerita yang terkumpul ada dua lokasi yang pernah dijadikan pemukiman oleh leluhur sebelum Desa Otam yang ditempati sekarang. Dua lokasi itu tersebut oleh Desa Otam dikenal dengan nama: Tudu Lipu', dan Lipu' Koyongan. Tudu Lipu' berjarak kira-kira $2500 \mathrm{~m}$ arah utara dari Desa sekarang dan dapat di tempuh 1 jam perjalanan kaki, sementara Lipu' koyongan berjarak kira-kira $500 \mathrm{~m}$ arah utara dari desa sekarang. Khususnya Lipu' Koyongan masih dapat di temui peninggalan-peninggalan yaitu, bukti-bukti yang jelas bahwa, leluhur Desa Otam pernah menetap dan tinggal di tempat tersebut dalam kurun waktu yang cukup lama, Marga Ginoga merupakan marga asli Desa Otam yang oleh generasi sesudahnya menjadi salah satu marga terbesar masyarakat. Dari cerita-cerita yang terkumpul Ginoga adalah Marga yang diambil dari nama orang, yang merupakan penduduk asli Desa Otam. Sosok Ginoga adalah merupakan pemimpin adat yang amat disegani pada kala itu, kemudian dari Ginoga lahiir keturunan-keturunan salah satunya adalah Adampe yang oleh penduduk juga dijadikan marga dan dari perkawinan-perkawinan lahir nama-nama seperti: Langke, Manggalupang, Nani, Moluat, Bemba, Biod, Inudi, Lantong Dan Lain-Lain yang belakangan Oleh penduduk dijadikan Marga. 
Nama Otam sendiri berasal dari jenis tumbuhan Rumput berduri, yang dalam bahasa Mongondow dikenal dengan nama Atam-atam yang pada waktu itu banyak tumbuh dilokasi tersebut. Dan oleh para leluhur pada waktu itu bersepakat menanamkan kampung tersebut dengan nama "OTAM" dengan adanya interaksi dari penduduk pada waktu itu masuk pula marga-marga seperti: Mokodompit, Hamim, Kolintama, Mokoginta, Paputungan, Pomayaan, Mamonto, Mokodongan, dan lain-lain. Sesudah pemerintahan Bingkolot, pengendali pemerintahan diserahkan kepada Hukum Mayor Sangian datu, Sangian Datu Memerintah kurang lebih 24 tahun. Selanjutnya sangian datu menyerahkan pemerintahan kepada Pongayo', pongayo' mengakhiri jabatan diperkirakan pada tahun 1878 .

\section{Pembagian Wilayah Desa}

Desa Otam dibagi dalam 4 (Empat) wilayah Dusun dan 8 wilayah RT. Tiap Dusun terbagi 2 (dua) wilayah RT. Tiap wilayah Dusun dibawah Pemerintahan seseorang Kepala Dusun dan tiap wilayah RT dipimpin oleh seorang Ketua RT.

Tabel 1. Luas Wilayah dan Jumlah Penduduk Menurut

\begin{tabular}{ccccc}
\multicolumn{5}{c}{ Data Desa } \\
\hline No & Dusun & Luas $\left(\mathbf{k m}^{2}\right)$ & $\begin{array}{c}\text { Penduduk } \\
\text { (jiwa) }\end{array}$ & $\begin{array}{c}\text { Kepadatan } \\
(\text { Penduduk/KM }\end{array}$ \\
\hline 1. & I & 7,8 & 475 & 16,42 \\
2. & II & 6,97 & 351 & 19,86 \\
3. & III & 7,1 & 328 & 21,65 \\
4. & IV & 8,236 & 308 & 26,74 \\
\hline & Jumlah & $\mathbf{3 0 , 1 0 6}$ & $\mathbf{1 , 4 6 2}$ & $\mathbf{8 4 , 7 6}$ \\
\hline
\end{tabular}

Tabel 1 menunjukkan bahwa jumlah penduduk yang ada di Desa Otam (Induk) yang terbagi atas empat dusun yaitu sebanyak 1.462 orang dengan luas wilayah $30.106 \mathrm{~km}^{2}$.

Tabel 2. Penduduk Menurut Jenis Kelamin

\begin{tabular}{cccc}
\hline \multirow{2}{*}{ Dusun } & \multicolumn{2}{c}{ Jenis Kelamin } & $\begin{array}{c}\text { Kepadatan } \\
\text { (Penduduk/KM }\end{array}$ \\
\cline { 2 - 3 } & $\begin{array}{c}\text { Luas } \\
\left(\mathbf{k m}^{\mathbf{2}}\right)\end{array}$ & $\begin{array}{c}\text { Penduduk } \\
\text { (jiwa) }\end{array}$ & \\
\hline I & 248 & 227 & 475 \\
II & 181 & 170 & 351 \\
III & 166 & 162 & 328 \\
IV & 158 & 150 & 308 \\
\hline Jumlah & $\mathbf{7 5 3}$ & $\mathbf{7 0 9}$ & $\mathbf{1 . 4 6 2}$ \\
\hline
\end{tabular}

Tabel 2 menunjukkan bahwa jumlah penduduk menurut jenis kelamin dengan jumlah penduduk perempuan yaitu sebanyak 709 orang sedangkan jumlah penduduk laki-laki sebanyak 753 orang dengan jumlah seluruh penduduk 1.462 orang yang terbagi di empat Dusun dimana jumlah penduduk laki-laki lebih banyak dari penduduk perempuan.

\section{Penduduk Menurut Mata Pencaharian}

Tabel 3 menunjukkan bahwa jenis pekerjaan di Desa Otam bermacam-macam namun meskipun begitu jumlah pekerja petani lebih banyak dibandingkan pekerjan lainnya dimana jumlah petani sebanyak 341 orang dari total masyarakat yang terdaftar yaitu 530 masyarakat petani. Sedangkan pekerja lainnya dapat kita lihat pada tabel diatas.

Tabel 3. Jenis Pekerjaan

\begin{tabular}{lc}
\hline \multicolumn{1}{c}{ Pekerjaan } & Jumlah (Orang) \\
\hline PNS & 31 \\
Perawat/Bidan & 3 \\
POLRI & 2 \\
Pensiunan & 25 \\
Kary. BUMN & 5 \\
Petani & 341 \\
Peternak & 1 \\
Pedagang & 19 \\
Tukang Kayu & 16 \\
Tukang Jahit & 3 \\
Tukang Listrik & 2 \\
Industuri Kecil & 8 \\
Buruh Serabutan & 74 \\
\hline Total/Pekerja & $\mathbf{5 3 0}$ \\
\hline
\end{tabular}

\section{Hasil Penelitian}

\section{Jumlah Responden Menurut Kelompok Umur}

Umur merupakan salah satu factor yang dapat mempengaruhi prilaku seseorang dalam melakukan atau mengambil suatu keputusan dan kemampuan bekerja secara optimal serta produktif akan tetapi seiring berjalannya waktu, umur manusia akan mengalami perubahan dalam hal pemahaman usia yang dapat mengakibatkan menurunnya tinggkat produktifitas seseorang dalam bekerja. Umur yang paling produktif dalam bekerja adalah umur antara 15 sampai 60 tahun.

\begin{tabular}{ccc} 
Tabel 4. Jumlah Responden Menurut Umur & \\
\hline $\begin{array}{c}\text { Umur } \\
\text { Responden/Thn }\end{array}$ & Jumlah (Orang) & Persentase (\%) \\
\hline $30-49$ & 29 & 58 \\
$50-69$ & 18 & 36 \\
$\geq 70$ & 3 & 6 \\
\hline Jumlah & $\mathbf{5 0}$ & $\mathbf{1 0 0}$ \\
\hline
\end{tabular}

Tabel 4 menunjukkan bahwa umur responden terbanyak yaitu antara $30-49$ dengan jumlah responden 29 orang dengan persentase $58 \%$, dan jumlah responden kedua yaitu antara umur 50-69 dengan jumlah responden 18 orang dengan persentase $36 \%$, sedangkan responden yang ketiga yaitu antara umur $\geq 70$ tahun keatas 
dengan jumlah responden 3 orang dengan persentase $6 \%$. Umur yang termasuk usia produktif $\leq 30$ tidak didapati dalam penelitian ini karena umumnya mereka keluar kota merantau dan sebagian sementara mencari pekerjaan.

\section{Jumlah Responden Menurut Tingkat Pendidikan}

Pendidikan merupakan salah satu faktor dalam menunjang peningkatan kualitas sumberdaya manusia guna untuk mencapai kesejahteraan hidup namun, juga sering dipakai sebagai tolak ukur tingkat kemajuan dalam masyarakat. Tingkat pendidikan responden Desa Otam (Induk), Kecamatan Passi Barat, Kabupaten Bolaang Mongondow adalah SD, SMP, SMA sedangkan lulusan perguruan tinggi belum ada pada responden yang di ambil dalam penelitian ini.

Tabel 5. Responden Menurut Tingkat Pendidikan

\begin{tabular}{lcc}
\hline $\begin{array}{c}\text { Tingkat } \\
\text { Pendidikan }\end{array}$ & $\begin{array}{c}\text { Jumlah } \\
\text { (Orang) }\end{array}$ & Persentase (\%) \\
\hline SD & 13 & 26 \\
SMP & 30 & 60 \\
SMA & 7 & 14 \\
\hline \multicolumn{1}{c}{ Jumlah } & $\mathbf{5 0}$ & $\mathbf{1 0 0}$ \\
\hline
\end{tabular}

Tabel 5 menunjukkan bahwa tingkat pendidikan responden terdiri dari tiga tingkatan yaitu responden yang tamat SD dengan jumlah responden 13 orang denga persentase $26 \%$, dan pendidikan responden yang tamat SMP yaitu 30 orang responden dengan jumlah terbanyak dari responden dengan jumlah persentase $60 \%$, sedangkan jumlah responden yang sampai di tingkat SMA yaitu berjumlah 7 orang responden dengan persentase 14\%. Dari tabel diatas menunjukkan bahwa tingkat pendidikan responden yang ada di Desa Otam (Induk) adalah rata-rata pada tingkat SMP, dan belum terdapat responden yang sampai pada perguruan tinggi.

\section{Profil Petani Dalam Memanfaatkan Pekarangan}

\section{Responden Menurut Kepemilikan Luas Lahan Pekarangan}

Luas lahan sangat berpengaruh terhadap jenis tanaman yang akan di tanam di pekarangan semakin luas lahan pekarangan maka semakin banyak pulah tanaman yang bisa di tanam, kepemilikan pekarangan berpotensi dalam pembentukan kelompok tani di Desa Otam dilihat dari pekarangan yang cukup luas.

\begin{tabular}{ccc} 
Tabel 6. Responden Menurut Luas Lahan Pekarangan \\
\hline $\begin{array}{c}\text { Luas lahan } \\
(\mathbf{m} 2)\end{array}$ & $\begin{array}{c}\text { Jumlah } \\
\text { Responden }\end{array}$ & Persentase (\%) \\
\hline$\leq 400,4$ & 48 & 96 \\
$\geq 1000$ & 2 & 4 \\
\hline Jumlah & $\mathbf{5 0}$ & $\mathbf{1 0 0}$ \\
\hline
\end{tabular}

Tabel 6 menunjukkan bahwa luas penguasaan lahan responden rata-rata antara $\leq$ 400,4 dengan jumlah orang responden 48 orang dengan persentase $96 \%$, sedangkan jumlah responden dengan luas lahan pekarangan antara $\geq 1000$ keatas berjumlah 2 orang responden dengan persentase $4 \%$.

\section{Status Kepemilikan Lahan Pekarangan Responden}

Menurut data yang telah dikumpulkan dari kepemilikan lahan responden adalah semua petani/responden memiliki lahan pekarangan dengan milik sendiri dan dimanfaatkan dengan menanam berbagai jenis tanaman di Desa Otam (Induk) Kecamatan Passi Barat Kabupaten Bolaang Mongondow.

Jenis Tanaman Yang di Tanam di
Pekarangan
Jenis tanaman yang tumbuh di
pekarangan sangatlah bermanfaat bagi masyarakat karena dapat membantu pendapatan kebutuhan keluarga. Baik jenis tanaman apotik hidup, dapur hidup, sayur-sayuran, dan tanaman buah-buahan.

\begin{tabular}{lcc}
\multicolumn{2}{c}{ Tabel 7. Responden Menurut Jenis Tanaman di Pekarangan } \\
\hline \multicolumn{1}{c}{ Jenis Tanaman } & Jumlah & Persentase (\%) \\
\hline Apotik hidup & 8 & 16 \\
Dapur hidup & 20 & 40 \\
Sayur-sayuran & 12 & 24 \\
Tanaman buah-buahan & 10 & 20 \\
\hline \multicolumn{1}{c}{ Jumlah } & $\mathbf{5 0}$ & $\mathbf{1 0 0}$ \\
\hline
\end{tabular}

Tabel 7 menunjukkan bahwa jenis tanaman yang ditanam responden sangat bervariasi. Tanaman apotik hidup dengan jumlah responden 8 orang yang menanam dengan persentase $16 \%$, tanaman dapur hidup yang ditanam responden 20 orang responden dengan jumlah persentase $40 \%$, sayur-sayuran dengan jumlah responden yang menanam 12 orang responden dengan persentase $24 \%$, dan tanaman buah-buahan yang ditanam responden dengan jumlah 10 orang responden dengan persentase $20 \%$. 
Jenis tanaman yang tumbuh dipekarangan responden yaitu: duku, alpokat, langsa, manggis, rambutan, sirsak, cingke, coklat, durian, kayu manis, mangga, bawang cina, sambiloto, matoa, kunyit, lengkuas, batang bawang, nanas, sayur gedi, mayana, balakama, jahe, temulawak, kulaci(solasi), kumis kucing, pisang, bawang merah, sawi, bayam puti, tomat, daun pandan, kol, bete, sayur leilem, terong, ketimun jepang, singkong, vanili, kemangi, dan cocor bebek. Pengelompokan jenis tanaman yang termasuk dalam apotik hidup contohnya: kumis kucing, sambiloto, jahe, dan temulawak. Tanaman yang termasuk dapur hidup contohnya: Lengkuas, bawang cina, kulaci (solasi), dan batang bawang. Tanaman yang termasuk sayuran contohnya: sawi, kol, wortel, tomat, sayur leilem dan ketimun Jepang. Sedangkan yang termasuk tanaman buah yaitu: duku, alpokat, langsa, sirsak, durian dan mangga.

Table 8. Jumlah Anggota Keluarga Responden

\begin{tabular}{ccc}
\hline Anggota Keluarga & $\begin{array}{c}\text { Jumlah } \\
\text { Responden }\end{array}$ & Persentase (\%) \\
\hline$\leq 3$ & 28 & 56 \\
$4-6$ & 20 & 40 \\
$7-8$ & 2 & 4 \\
\hline Jumlah & $\mathbf{5 0}$ & $\mathbf{1 0 0}$ \\
\hline
\end{tabular}

Tabel 8 menunjukkan bahwa jumlah anggota keluarga $\leq 3$ kurang dari 3 anggota keluarga berjumlah 28 orang responden dengan persentase $56 \%$, dan jumlah anggota keluarga 4 6 orang responden berjumlah 20 orang responden dengan persentase $40 \%$, sedangkan jumlah anggota keluarga $7-8$ orang responden dengan jumlah anggota keluarga 2 orang responden dengan persentase $4 \%$. Pada tabel kita bisa melihat jumlah anggota responden paling banyak adalah rata-rata 3 orang karena kepala keluarga tidak terhitung.

\section{KESIMPULAN DAN SARAN}

\section{Kesimpulan}

Hasil penelitian di Desa Otam (Induk) profil petani yang menanam apotik hidup dengan persentase $16 \%$ merupakan responden yang paling sedikit, dan responden yang menanam tanaman dapur hidup dengan persentase $40 \%$ merupakan responden yang paling banyak menanam di pekarangan. Sedangkan responden yang menanam sayuran-sayuran $24 \%$, dan yang menanam buahbuahan $20 \%$. Pemanfaatan pekarangan masih perlu ditingkatkan oleh petani.

\section{Saran}

Pemerintah Desa Otam (Induk) perlu memfasilitasi masyarakata petani yang punya lahan pekarangan untuk pembentukan kelompok tani pekarangan agar masyarakat bisa mendapatkan bantuan dari pemerintah khususnya dari dinas pertanian agar petani termotivasi dalam memanfaatkan pekarangan, kelompok tani pekarangan belum menjadi perhatian pemerintah sedangkan lahan pekarangan yang ada dipedesaan cukup luas dan bisa menghasilkan berbagai macam tanamam baik buah-buahan maupun tanaman sayursayuran.

\section{DAFTAR PUSTAKA}

Ayuningtias, A. Y., 2012. Pemberdayaan Masyarakat Petani dalam Meningkatkan Hasil Panen melalui Program Gapoktan di Kecamatan Moyudan. Diakses 6 Januari 2020. http://nadrayunia. blogspot.com/20 12/06/pemberdayaan-masyarakat-petanidal am.html.

Handoko. 2008. Pengembangan Sumber Daya Manusia. Html http: //www. Kajian pustaka. com/diakses tgl 3 September. 2016.

Istiqomah, Nurul. 2018. Pemberdayaan Ekonomi Keluarga dalam Meningkatkan Penghasilan Melalui Kelompok Pengrajin Batu Bata: Studi Deskriptif Jln. Kampung Gandaria Desa Cipayung Kecamatan Cikarang Timur Kabupaten Bekasi. PhD diss., UIN Sunan Gunung Djati Bandung.

Welang, F.R., Dumais, J.N. and Sendow, M.M., 2016. Analisis Pendapatan USAhatani Padi Sawah Berdasarkan Musim Panen di Kelurahan Taratara Satu Kecamatan Tomohon Barat Kota Tomohon. AGRISOSIOEKONOMI, 12(2A): 107-124. 